\title{
Critical Exploration of the new NMC Future Nurse: Standards of Proficiency for Registered Nurses
}

Dr Jacqueline Leigh and Professor Debbie Roberts, August 2018

\section{Introduction}

Following a two year process that included consulting and working alongside key stakeholder groups such as students, educators, healthcare professionals, charities and patient groups from across the UK, The Nursing and Midwifery Council (NMC) launched their Future nurse: Standards of proficiency for registered nurses (NMC 2018a). These new and compulsory standards are available for use in curricula by Approved Education Institutions (AEI's) from the $28^{\text {th }}$ January 2019. Only students who are part way through their pre-registration programme having commenced at an AEI prior to January 2019 will continue on the existing curriculum with the current NMC standards.

The NMC refer to the standards as:

"Ambitious new standards that set out the skills and knowledge the next generation of nurses will learn to enable them to deliver world class care" (NMC 2018b).

The standards are set out in three parts:

Part 1: Standards framework for nursing and midwifery education- this document provides a framework of five headings that underpin nurse education and training:

1. Learning culture

2. Educational governance and quality

3. Student learning and empowerment

4. Educators and assessors

5. Curricula and assessment

Part 2: Standards for student supervision and assessment- this document sets out the expectations for the learning, support, supervision and assessment (of theory and practice) of students in the practice environment.

Part 3: Programme standards, which are the standards specific for each pre-registration or postregistration programme- this document set out the legal requirements for all pre-registration nursing education programmes.

Collectively the three documents contain proficiencies that specify the knowledge and skills that registered nurses must demonstrate when caring for people of all ages and across all care settings, reflecting what the public can expect nurses to know and be able to do in order to deliver safe, compassionate and effective nursing care. A key message and something which remains consistent with the current pre-registration standards is the fundamental requirement for partnerships between Approved Education Institutions (AEIs) and healthcare organizations to provide the practice based learning for the student nurses:

"(AEIS) are responsible for working with practice learning partners to manage the quality of their educational programmes. Overall responsibility for the day-to-day management of the quality of any educational programme lies with an AEI in partnership with practice learning partners who provide opportunities for practice experience to nursing and midwifery students" (NMC 2018a:4). 
This paper focuses on Part 2: standards for student support and assessment, exploring the key differences between the new and old sets of standards. We offer some personal perspectives about the potential impact of these new standards, particularly around the personnel responsible for supervising and assessing students in clinical practice and the potential preparation for the role. Partnership between AEls and its practice partners are also explored.

Pre 2018 Standards: Standards to Support Learning and Assessment in Practice: NMC Standards for Mentors, Practice Teachers and Teachers: Exploring the Pivotal Role of Mentor and Sign-Off Mentor

The NMC document: Standards to Support Learning and Assessment in Practice: NMC Standards for Mentors, Practice Teachers and Teachers (NMC 2006, 2008) adopted a four stage framework that defined and described the knowledge and skills that nurses' and midwives must possess at each stage to support and assess students on NMC-approved pre- and post-registration programmes. Although the Department of Health has long asserted the positon that supervising students is part of every professional practitioner's role (DH 2000), the role of other professionals in supporting students has been extremely limited, often relegated to a supporting statement contained within the students practice assessment document. Whereas, the literature concerning the importance of mentors to learning is plentiful (Leigh and Roberts 2017, Hunt et al. 2016, Black et al. 2014), mentors are currently expected to spend $40 \%$ of their time with the student per week as their role is seen as pivotal to student learning and assessment in clinical practice. Preparation for the role (prescribed by the NMC $(2006,2008)$ consisted of a minimum of 10 days, at least 5 of which should be protected learning time over a period of 3 months in both academic and practice settings) was not proportionate to the importance that the role played within nurse education (Leigh and Roberts 2017), nor did it always produce a mentor that enthused about the role at the end of their programme (Nettleton and Bray, 2008; Lauder et al, 2008). Furthermore, questions were raised about the long-term sustainability and quality assurance processes of the role of the sign-off mentor (Andrews et al, 2010).

\section{Part 2: Standards for student Supervision and Assessment (NMC 2018): Implications for Practice Teaching, Learning and Assessment}

The NMC are proud of their new standards, providing increased opportunity for other registered health and care professionals as well as nurses and midwives to support and improve the quality of student learning. Jackie Smith, the former recent NMC Chief Executive and Registrar reports how the NMC have:

"Overhauled the way universities train nurses and midwives. They'll be given more flexibility to harness new ways of working and embrace technology so they can equip the nurses and midwives of tomorrow with the skills they need to deliver world class care for years to come." (NMC 2018b).

\section{Supervision and Assessment of Students:}

Contained in Part 2 are changes to the way that students are supported in clinical practice with the NMC not only shifting focus away from the pivotal role of mentor but introducing two new roles: those of practice supervisor and practice assessor.

\section{The Practice Supervisor}

The new standards suggest that all Registrants should be able to undertake the role of practice supervisor (indeed all new Registrants exiting nurse education programmes will be prepared for this JL \&DR $28^{\text {th }}$ August 2018 
new aspect of their work). Each AEI in partnership with their placement providers will be developing their governance arrangements to prepare and support the practice supervisors. It is important to remember that the current standards will be effective for some time to come as the new standards dovetail in; therefore busy clinical nurses who currently act as mentors for students may also have to take on the supervisor and/or assessor role. The NMC are also clear that students should actively participate in their own education, learning from a range of people across a variety of settings, including service users, registered and non-registered individuals, and other students as appropriate:

"All NMC registered nurses and midwives are capable of supervising students, serving as role models for safe and effective practice. Students may be supervised by other registered health and social care professionals" (NMC 2018c: 6).

This widening of the supervisory role is a welcome departure from the current profession centric approach to mentorship (Andrews et al 2010), offering authentic inter-professional teaching and learning opportunities. With it comes the opportunity to think differently about practice placements and the environment where teaching and learning takes place. For example, this could open up opportunities for student nurses to work alongside key personnel who deliver social care, social prescribing together with those working in new and emerging roles within unscheduled care. Thinking creatively about practice placements brings opportunities for inter-professional supervision, with students learning about the roles of other disciplines and how to collaborate in a team (Leigh and Roberts 2017). These interactions are suggested to be relatively easy to introduce without the need for radical changes to the structure of the placements or the curricula (Lait et al 2011). A summary of role and responsibilities for the practice supervisor are identified in table 1.

\section{Table 1 Summary of Role and Responsibilities for the Practice Supervisor}

\begin{tabular}{l|l|}
$\begin{array}{l}\text { Serve as role models for safe and effective } \\
\text { practice in line with their code of conduct }\end{array}$ & $\begin{array}{l}\text { Support and supervise students, providing } \\
\text { feedback on their progress towards, and } \\
\text { achievement of, proficiencies and skills }\end{array}$ \\
$\begin{array}{l}\text { Support learning in line with their scope of } \\
\text { practice to enable the student to meet their } \\
\text { proficiencies and programme outcomes }\end{array}$ & $\begin{array}{l}\text { Receive ongoing support to participate in the } \\
\text { practice learning of students. }\end{array}$ \\
\hline
\end{tabular}

\section{Assessment of Students: The Assessor Role}

Under the new standards, the NMC make clear that student assessments will be:

"Evidence based, robust and objective. Assessments and confirmation of proficiency.... based on an understanding of student achievements across theory and practice" (NMC 2018c:8)

To achieve this there will be two types of assessor roles:

1. Practice assessor

2. Academic Assessor

The NMC provide clear roles and responsibilities for the practice assessor and academic with a summary provided in table 2 and 3.

Table 2 Summary of Role and Responsibilities for the Practice Assessor

Conduct assessments to confirm student Works in partnership with the nominated achievement of proficiencies and programme academic assessor to evaluate and recommend 


\begin{tabular}{|l|l|}
\hline outcomes for practice learning & $\begin{array}{l}\text { the student for progression for each part of the } \\
\text { programme, in line with programme standards } \\
\text { and local and national policies }\end{array}$ \\
\hline $\begin{array}{l}\text { Make assessment decisions that are informed by } \\
\text { feedback sought and received from practice } \\
\text { supervisors }\end{array}$ & $\begin{array}{l}\text { Provide sufficient opportunities for the practice } \\
\text { assessor to periodically observe the student } \\
\text { across environments in order to inform decisions } \\
\text { for assessment and progression }\end{array}$ \\
\hline $\begin{array}{l}\text { Make and record objective, evidenced-based } \\
\text { assessments on conduct, proficiency and } \\
\text { achievement, drawing on student records, direct } \\
\text { observations, student self-reflection, and other } \\
\text { resources }\end{array}$ & \\
\hline
\end{tabular}

Table 3 Summary of Role and Responsibilities for the Academic Assessor

Collate and confirm student achievement of proficiencies and programme outcomes in the academic environment for each part of the programme; making and recording objective, evidence based decisions and recommendations for progression, drawing on student records and other resources

Have an understanding of the student's learning and achievement in practice
Works in partnership with a nominated practice assessor to evaluate and recommend the student for progression for each part of the programme

Unlike the current mentor role, the new standards prohibit individuals to simultaneously work in the role of practice supervisor and practice assessor for the same student. There is however, a noticeable expectation of interplay between the roles of supervisor and practice assessor with the NMC expecting that clear and robust communication channels are developed so that the assessment and progression of the student is informed by feedback from a range of personnel. This indicates that assessment should be detailed, robust and thorough. The NMC also make the nature of supernumerary status explicit in that students in practice or work-placed learning environments must be supported to learn without being counted as part of the staffing required for safe and effective care in that setting. Supernumerary status is elaborated upon within the new standards with the suggestion that supervision can be more flexible; based on individual student need as the student progresses through an education programme, with students having periods of allocated, supported learning time.

\section{Role preparation}

Different too is the deliberate removal of the prescriptive approaches to the education and development of the supervisor and assessor, that under the pre 2018 standards led to the proliferation of credit and non- credit bearing programmes that prepared the qualified nurse for the role of mentor under the current standards. Gone too is the need for compliance with the 'live' mentorship recognition and requirements for the stage 4 teacher award. This has been replaced by what feels like a flexible and more pragmatic regulatory framework that is more akin to other health professional groups. Leigh and Roberts (2017) make comparisons to The Health and Care Professions 
Council (HCPC) that have no specific requirements or expectations for the development of their practice based educators; the specific requirements for the length or content of any training is decided by individual education providers. The NMC require the development of systems that requires partnership working between $A E l s$ and practice partners to ensure that:

Practice supervisors "receive ongoing support to prepare, reflect and develop for effective supervision and contribution to, student learning and assessment; and have understanding of the proficiencies and programme outcomes they are supporting students to achieve" (NMC 2018c: 6)

Practice assessors "undertake preparation or evidence prior learning and experience that enables them to demonstrate achievement of minimum outcomes" (NMC 2018c:10). These include conducting objective, evidence based assessments of students; providing constructive feedback to facilitate professional development in others, and demonstrating knowledge of the assessment process and their role within it.

Academic assessors: "are working towards or hold relevant qualifications as required by their academic institution and local and national policies" " (NMC 2018c: 11).

The responsibility for supervision and assessment of students remains with those who will continue to have to juggle the increasing demands of delivering patient care with their supervisory or assessor roles. We would caution AEI's and placement providers to ensure that appropriate arrangements are in place to adequately prepare supervisors and assessors for their imminent roles; , in order to avoid those engaging in such roles from feeling ill prepared and unsupported. The new standards do allow greater independence of assessment, offer the potential for greater innovation by placement providers, and the development of placements in a wider range of settings. These are exciting times for AEls and practice partners who have been given permission to be creative and to think differently (within regulatory boundaries) to innovate around placement assessment by drawing on the expertise of other healthcare professionals thus opening up student learning in diverse and far ranging practice placement environments. Although, whether our interdisciplinary colleagues are ready for such a challenge remains to be seen.

In terms of who should take on the role of practice assessor, this will be largely determined locally with agreements between individual AEl's and placement providers. The role could be fulfilled by current mentors or sign-off mentors. The NMC do provide some guidance as to what knowledge, skills and behaviours are expected of the assessor to facilitate effective planning, systems development and educational preparation that will be necessary to ensure sufficient supervisors and assessors:

Knowledge: objective evidence based assessments; constructive feedback; knowledge of the assessment process and their role within it; knowledge of the curriculum and proficiencies required

Skills: Conducting objective evidence based assessments; providing constructive feedback

Behaviours: interpersonal communication skills, relevant to student learning and assessment

Ongoing development: There is an expectation that both supervisors and assessors will be provided with ongoing support and training and will be able to reflect and develop in the role; individuals are required to continue to proactively develop their professional practice and knowledge in order to fulfil their role. In reality this will be achieved in different and contemporary ways and our examples include: through attendance at conferences; engaging in simulation; use of coaching skills; action learning; and distance learning. The similarities in those knowledge, skills, behaviours and professional development requirements for the supervisor and assessor compared to other JL \&DR $28^{\text {th }}$ August 2018 
professions including medicine, occupational therapy, and social work, makes inter-professional preparation for the educator role a reality. However, all of this activity will take time, and this is perhaps the most contentious issue. For example, where AEIs adopt a trimester approach to the curriculum, each trimester may become an assessment point as a part of the programme (meaning that students may require three practice based assessments each year). A conservative estimate of the time taken to perform such a detailed evidence based assessment is perhaps two hours, per assessment per student $=1$ day of assessment per student per year. In an institution where there are perhaps 500 students within a single cohort and three cohorts (first, second and third year students) in place at any one time, it is easy to see that some placement providers could struggle to ensure that clinicians have sufficient time allocation within what is already a heavy workload, to undertake student practice based assessments whilst maintaining a clinical role. This is going to be particularly difficult in rural areas where assessors may be expected to follow the student across different clinical settings or a part of the programme. The concern being that the assessment will be rushed and potentially superficial and subsequently perhaps not given the status that the system itself has been designed to promote.

\section{Summary and recommendations:}

In 2017 we produced a paper for BNJ that explored the implication of the then draft standards and at the end of the paper we offered a summary and recommendations (Leigh and Roberts 2017). Now that the definitive standards have been published we continue to take the position that the NMC are offering flexibility regarding practice based learning with AEls and practice partners around the UK, like ourselves, working collaboratively trying to make sense of the new roles that have emerged, setting the benchmark for quality teaching and learning in clinical practice. Reconsidering models of student support is imperative; as a result new coaching models for developing student nurse's clinical leadership are being implemented. Coaching models that utilise peer learning are perfect for the new standards that require students to take responsibility for their own learning. (Leigh et al. 2018).

Systems need developing to operationalise the role of academic supervisor, taking into account that student practice placements are often geographically dispersed. At the same time the Department of Health 2017 strategy to fund an extra 10,000 student nurses, midwives and allied health professionals by 2020 means that again there is an increased role for the academic assessor. Strategies to support the role include the application of electronic practice documentation so that the collaborations required can be administered on-line.

Healthcare organisations currently report difficulties balancing the requirements for mentors to be able to attend preparation sessions for the role. Developing governance systems that ensure that assessors and supervisors are adequately prepared and supported for their student facing role is paramount. Again we have not shifted our opinion, and agree with Henderson and Eaton that for whichever model of supporting clinical learning is adopted; unless a culture that establishes the value of teaching and learning in practice is recognised and fostered by senior managers, new ventures are likely to fail (Henderson and Eaton 2013). Realising the worth of clinical learning at the bedside requires a major shift in terms of buy-in from senior managers and staff; indeed perhaps it is time to acknowledge the need for those who are responsible for the clinical learning or assessing to be supernumerary? This would mitigate against undertaking the role whilst caring for sick people. The key message remains the same- be creative and entrepreneurial adopting educational improvement and transformation tools and techniques to achieve the cultural shift required; 
through exemplary leadership by all involved (Leigh et al. 2017). We remain of the view that flexible should not mean reduced quality.

\section{References}

Andrews, M., Brewer, M., Buchan, T., Denne, A., Hammond, J., Hardy, G., Jacobs, L., McKenzie, L., West, S. (2010). Implementation and sustainability of the nursing and midwifery standards for mentoring in the UK. Nurse Education in Practice 10 (2010) 251-255

Black, S., Curzio, J., and Terry, L. 2014. Failing a student nurse: A new horizon of moral courage. Nursing Ethics. 2(2): 224-238.

Department of Health. 2000. Meeting the challenge: A strategy for the Allied Health Professionals. London, $\mathrm{DOH}$

Health and Care Professions Council (HCPC) (2014) Standards of Education and Training, London: http://www.hpc-uk.org/aboutregistration/standards/sets/(accessed 23rd June 2018)

Henderson A., and Eaton E. 2013. Assisting nurses to facilitate student and new graduate learning in practice settings: What 'support' do nurses at the bedside need? Nurse Education in Practice. 13: 197-201

Hunt L A, McGee P, Gutteridge R, Hughes M. (2016) Manipulating mentors' assessment decisions: Do underperforming student nurses use coercive strategies to influence mentors' practical assessment decisions? Nurse Education in Practice. Doi: 10.1016/j.nepr.2016.08.007

Lait. J., Suter. E., Arthur. N., and Deutschlander. S. 2011. Interprofessional mentoring: Enhancing students' clinical learning. Nurse Education in Practice. 11 (3): 211-215, https://doi.org/10.1016/j.nepr.2010.10.005 (accessed 23rd June 2018)

Lauder, W., Roxburgh, M., Holland, et al., 2008. The Report of the Evaluation of Fitness to Practice Pre-Registration Nursing and Midwifery Curricula Project. Commissioned by NHS Education for Scotland.

Leigh J A., Littlewood L., (2018), providing the right environment to develop new clinical nurse leaders, British Journal Nursing 27 (6), 341-343

Leigh J A., Littlewood L., Heggs K., (2018) Using simulation to test use of coaching in clinical placements, Nursing Times 114 (4): 44-46

Leigh. J A., Roberts D., 2017 Implications for operationalising the new education standards for nursing. British Journal of Nursing. 28 (10): 2-4

Leigh J A., Williamson T., Rutherford J., (2017) Stakeholder Perspectives of an Approach to Healthcare Leadership Development through Use of a Multidimensional Leadership Development Conceptual Model, International Journal of Practice-based Learning in Health \& Social Care, 5 (1), 77-97

Nettleton, P. and Bray, L. 2008. Current mentorship schemes might be doing our students a disservice. Nurse Education in Practice. 8, 205-212.

Nursing and Midwifery Council (2006) Standards to Support Learning and Assessment in Practice: NMC Standards for Mentors, Practice Teachers and Teachers. NMC, London. 
Nursing and Midwifery Council (2008) Standards to Support Learning and Assessment in Practice: NMC Standards for Mentors, Practice Teachers and Teachers. NMC, London

Nursing and Midwifery Council (2018a) Future nurse: Standards of proficiency for registered nurses, London, NMC https://www.nmc.org.uk/globalassets/sitedocuments/education-standards/futurenurse-proficiencies.pdf (accessed 23rd June 2018)

Nursing and Midwifery Council (2018b) New NMC standards shape the future of nursing for next generation, https://www.nmc.org.uk/news/press-releases/new-nmc-standards-shape-the-futureof-nursing-for-next-generation/ (accessed $23^{\text {rd }}$ June 2018)

Nursing and Midwifery Council (2018c) Realising professionalism: Standards for education and training Part 2: Standards for student supervision and assessment, https://www.nmc.org.uk/globalassets/sitedocuments/education-standards/student-supervisionassessment.pdf (accessed $24^{\text {th }}$ June 2018)

Roberts D. 2011. Grading the Performance of clinical skills: Lessons to be learned from the performing arts. Nurse Education Today, 31 (6): 607-610 